\title{
Response to Dr. Zimmern
}

\author{
Dirk Stemerding
}

Received: 1 October 2010 / Accepted: 6 October 2010 /Published online: 6 November 2010

(C) The Author(s) 2010. This article is published with open access at Springerlink.com

In his letter, Dr Zimmern seeks to dispel the notion that community genetics is unique and different from public health genomics, and he argues instead that both fields are "in essence one single discipline". Let me, first of all, clarify that a comparison of both fields was not the primary aim of my commentary. My commentary is first of all based on a detailed study of the contents of the former journal Community Genetics. The aim of this study was a deeper understanding of the way in which the proponents of this field have defined their ambitions and agenda; however, the years in which the volumes of Community Genetics were published was also the time in which public health genomics began to emerge as a new field. So, I also became interested in attempts of the proponents of community genetics to define the "uniqueness" of their own endeavour "in the light of" public health genomics. In doing so, I further added my own reflections on this new and emerging field. As I have observed in my commentary, community genetics and public health genomics are moving from different starting points but nevertheless are heading, in several respects, to a similar approach. Indeed, given my own observations on this point, I can agree with most of what Dr. Zimmern has to say about the close relation between the two fields; however, even though both fields have many elements in common, they do not simply coincide in terms of their agenda and ambitions. This also becomes clear from Dr. Zimmern's own perception of community genetics as a "subset" of public health genomics.

We find, in one of the editorials in the journal Community Genetics, a similar distinction in terms of the extension of both fields. Ironically, in this case, ten Kate conversely defines public health genomics as a nuclear family "within the extended family of community genetics" (ten Kate 2000). More important of course than these different and conflicting

D. Stemerding $(\bowtie)$

Faculty of Management and Governance, Department of Science, Technology and Policy Studies, University of Twente, P.O. Box 217, 7500 AE Enschede, The Netherlands e-mail: d.stemerding@utwente.nl demarcations, are the different starting points from which both fields are approaching each other. The different roots of community genetics and public health genomics remain of crucial importance for our understanding of the particular focus defining each field. On the one hand, "empowerment of individuals with regard to informed decision-making" (ten Kate 2008), on the other hand, "translation of genome-based health information and technologies into health interventions" (Knoppers and Brand 2009).

In his letter, Dr. Zimmern suggests that, "history aside", these starting points are only a matter of a slight difference in emphasis. In my view, however, the difference between these starting points reflects an important tension. This tension is marked, on the one hand, by an individual rights perspective rooted in a tradition of reproductive decision-making and on the other hand, by an endeavour to improve population health rooted in public health values. This tension indeed also characterizes our modern health care landscape, but it involves a specific challenge, as I have argued in my commentary, for both community genetics and public health genomics. I see this challenge as highly important for the future development of both fields. That is why we should not, I think, try to dispel the notion of difference between community genetics and public health genomics, but seek to understand the different starting points from which both fields are facing this challenge, thus inviting further reflection and debate.

Open Access This article is distributed under the terms of the Creative Commons Attribution Noncommercial License which permits any noncommercial use, distribution, and reproduction in any medium, provided the original author(s) and source are credited.

\section{References}

Knoppers BM, Brand A (2009) From community genetics to public health genomics - what's in a name? Pub Health Genom 12:1-3 ten Kate LP (2008) Community genetics in the era of public health genomics. Community Genet 11:1 